\title{
Maternal plasma fatty acid composition and pregnancy outcome in adolescents
}

\author{
S. J. Wheeler ${ }^{1}$, L. Poston ${ }^{2}$, J. E. Thomas ${ }^{1}$, P. T. Seed ${ }^{2}$, P. N. Baker ${ }^{3}$ and T. A. Sanders ${ }^{1}$ \\ ${ }^{1}$ Nutritional Sciences Division, King's College London, Franklin Wilkins Building, 150 Stamford Street, London SE1 9NH, \\ UK, ${ }^{2}$ Division of Reproduction and Endocrinology, King's College London, 10th Floor North Wing, St Thomas' Hospital, \\ London SE1 7EH, UK and ${ }^{3}$ Maternal and Fetal Health Research Group, School of Laboratory and Clinical Sciences, \\ University of Manchester, St Mary's Hospital, Manchester M13 OJH, UK
}

Pregnancy during adolescence carries a greater risk of preterm delivery and small-for-gestational age (SGA) birth compared with pregnancy during adulthood ${ }^{(1,2)}$ and this finding has been attributed in part to poorer maternal nutritional status ${ }^{(3)}$. Recent meta-analyses of randomized controlled trials in adults have suggested that supplementation with $n-3$ long-chain PUFA (LCP) extends the duration of gestation ${ }^{(4-6)}$ and observational data have also suggested a protective effect on fetal growth ${ }^{(7)}$.

The present study has addressed the hypothesis that low maternal LCP status adversely influences pregnancy outcome.

Adolescents ( $n$ 500; age 14-18 years) were recruited at $\leq 20$ weeks of gestation. Frequency of consumption of oily fish was determined by questionnaire (at recruitment and during the third trimester). The fatty acid composition of plasma lipids during the third trimester was determined in 283 subjects. Principal components analysis (PCA) was used to derive components, which were divided into tertiles. Pregnancy outcomes were then compared by tertile, adjusting for potentially-confounding variables.

Of the participants $69 \%$ reported never eating oily fish during pregnancy, although consumption was not associated with a shorter duration of gestation, lower customized birth weight or higher incidence of SGA birth. PCA of the fatty acids composition of plasma lipids identified two components: 'low PUFA:SFA (P:S)' and 'high $n-3$ LCP'. There were no differences between tertiles of the 'high $n-3$ LCP' component and gestational age at delivery $(P=0.80)$, customized birth weight $(P=0.38)$, or incidence of SGA birth $(P=0.16)$, nor were there any associations between the 'low P:S' component and pregnancy outcome.

Lower proportions of $n-3$ LCP in plasma lipids are not associated with greater risk of adverse pregnancy outcomes in adolescents.

Supported by a grant from the UK Big Lottery Fund (RG/1/010095117) administered through Tommy's (UK charity registration no. 1060508), which also provided additional funding.

1. Jolly MC, Sebire N, Harris J et al. (2000) Obstet Gynecol 96, 962-966.

2. Hediger ML, Scholl TO, Schall JI et al. (1997) Ann Epidemiol 7, 400-406.

3. Scholl TO, Hediger ML \& Schall JI (1997) Ann N Y Acad Sci 817, 292-301.

4. Makrides M, Duley L \& Olsen SF (2006) Cochrane Database of Systematic Reviews, issue 3, CD003402. http://www.cochrane.org/reviews/en/ ab003402.html.

5. Szajewska H, Horvath A \& Koletzko B (2006) Am J Clin Nutr 83, 1337-1344.

6. Horvath A, Koletzko B \& Szajewska H (2007) Br J Nutr 98, 253-259.

7. van Eijsden M, Hornstra G, van der Wal MF et al. (2008) Am J Clin Nutr 87, 887-895. 